\title{
The C-Cube: an endoscopic solution in the time of COVID-19
}

During the COVID19 pandemic, personal protective equipment (PPE) has been widely used by clinicians and nurses, with a progressive lack of storage and recurring need for supplies.

Considering the high number of asymptomatic patients, and the not-uncommon need for endoscopic procedures for COVID-19-infected patients [1], it would be prudent to reduce as much as possible the exposure of healthcare workers who operate at short physical distance from patients, especially in hospitals with a high density of COVID-19 cases. Although stratification of preoperative patients and proper training for the entire endoscopy staff are mandatory [2], clinicians have been forced to improvise and invent novel protective barriers in order to reduce aerosol spread during high-risk procedures, such as tracheal intubation, bronchoscopy or gastrointestinal endoscopy, which require level 3 personal protection [3].

Here we present our endoscopic COVID Cube called the "C-Cube," which has been specifically designed with multiple entryways for direct management of the head-neck area, and mechanically protects clinicians who have direct contact with the oral cavity during invasive procedures ( $\mathbf{F i g} \mathbf{\text { . }}$ ). The barrier is a mobile transparent protective box, which is composed of inexpensive and easy-tofind materials (Plexiglas) and is completely washable. The box has two elliptical ports in the posterior wall for the anesthesiologist's hands, and one port for endoscopic access on the right side ( Fig.2). In addition, the openings are covered by a single-use plastic layer with a central longitudinal linear cut that allows physical access of the operator's hands or instruments (endoscope, laryngoscope, endotracheal tube), further reducing any possible leakage of contaminated air.

Other interesting homemade solutions have been described for either endoscopic [4] or anesthesiologic purposes

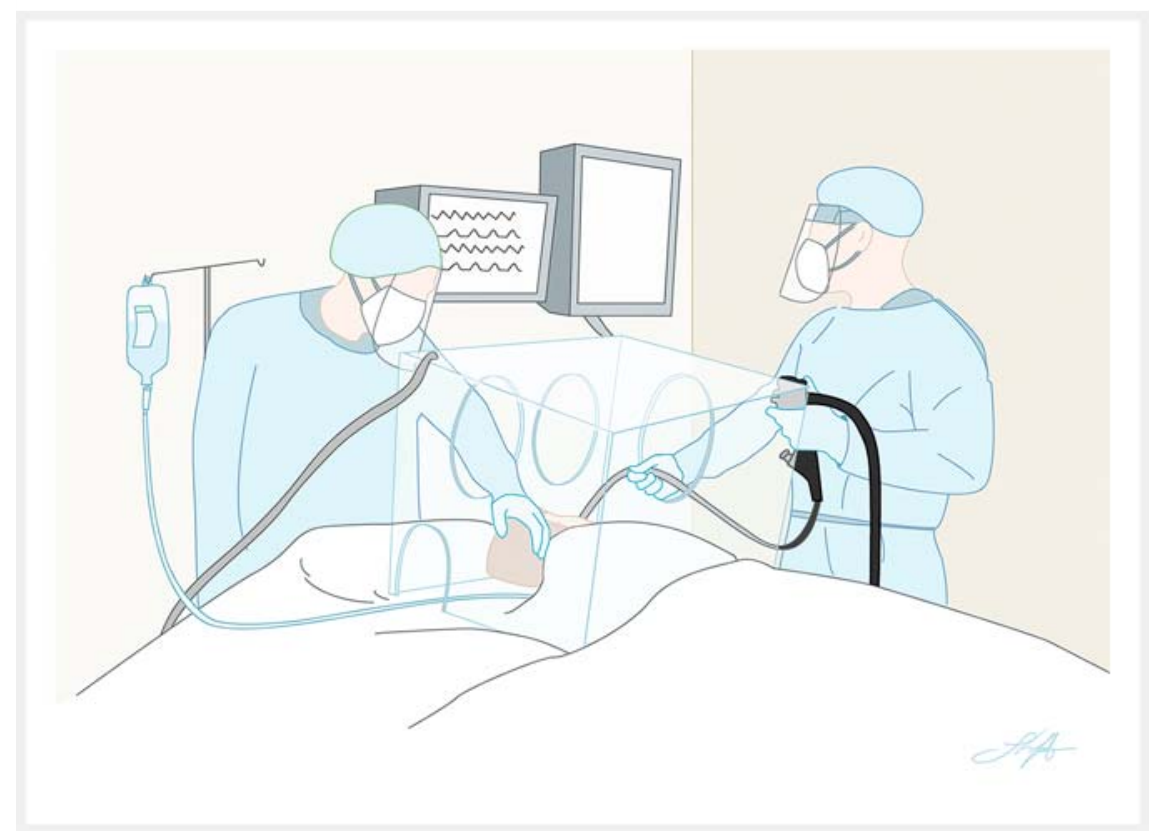

- Fig. 1 Illustration of the correct application of the "C-Cube" in the operative endoscopy room. The shield covers the head of the patient and generates an "aerosol isolated box" thanks to the direct airflow suction through the exit aspiration channel. Source: Federico Amata.

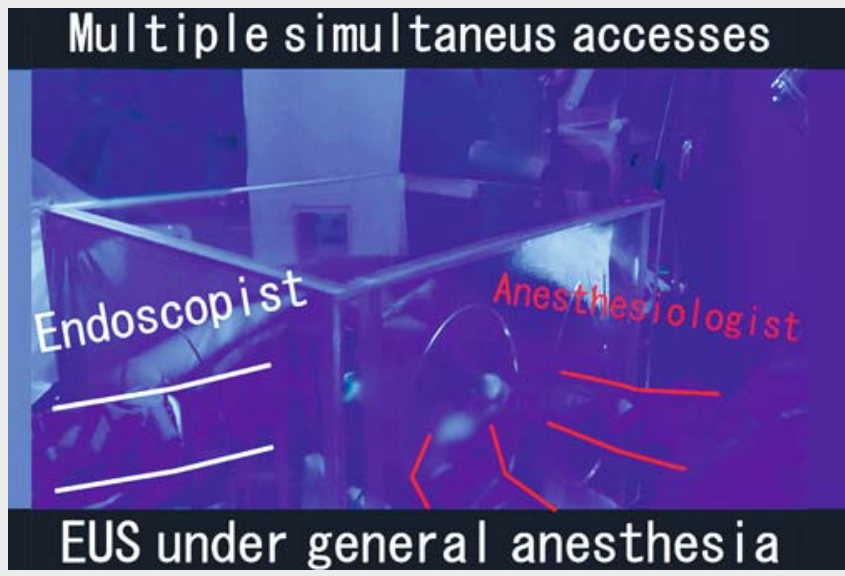

$\checkmark$ Video 1 Our personal experience of endoscopic procedures performed during the COVID-19 pandemic: technical demonstration using the "C-Cube" endoscopic box.

[5], but a single system with practical access for both anesthesiologist and endoscopist is preferable in our opinion. We have already tested the C-Cube for interventional esophagogastroduodeno- scopy, endoscopic ultrasound, and endoscopic retrograde cholangiopancreatography under general anesthesia, with considerable efficacy ( $\triangleright$ Video 1). 


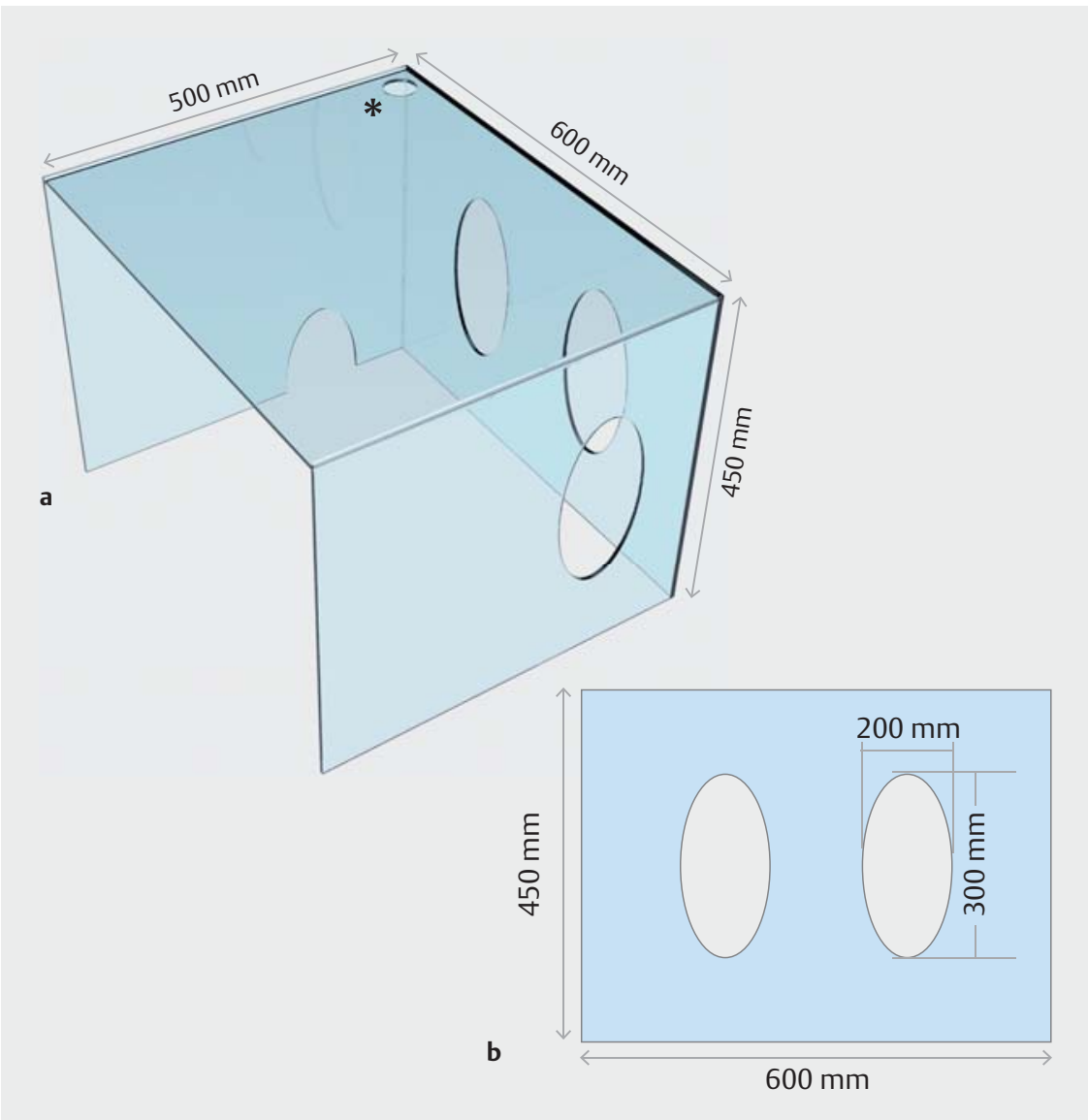

- Fig. 2 The structural characteristics of the "C-Cube". a General three-dimensional overview (asterisk: exit aspiration channel). b The posterior wall. There is also a small aperture on the bottom of the left side for the passage of monitoring cables or peripheral lines.

Although this novel system lacks scientific validation, the barrier might provide enhanced protection for all healthcare workers in the endoscopy room when combined with appropriate PPE. In addition, the "C-Cube" may guarantee acceptable comfort during therapeutic procedures, with low additional costs and easy reproducibility.

\section{Endoscopy_UCTN_Code_TTT_1AU_2AC}

\section{Acknowledgments}

We thank Federico Amata for graphics assistance.

\section{Competing interests}

The authors declare that they have no conflict of interest.

\section{References}

[1] Repici A, Aragona G, Cengia G et al. Low risk of covid-19 transmission in Gl endoscopy. Gut 2020. doi:10.1136/gutjnl-2020-321341

[2] Gralnek IM, Hassan C, Beilenhoff U et al. ESGE and ESGENA Position Statement on gastrointestinal endoscopy and the COVID19 pandemic. Endoscopy 2020. doi:10.1055/a-1155-6229

[3] Weissman DN, de Perio MA, Radonovich LJ. COVID-19 and risks posed to personnel during endotracheal intubation. JAMA 2020 doi:10.1001/jama.2020.6627

[4] Marchese M, Capannolo A, Lombardi L et al. Use of a modified ventilation mask to avoid aerosolizing spread of droplets for short endoscopic procedures during coronavirus covid-19 outbreak. Gastrointest Endosc 2020. doi:10.1016/j.gie.2020.03.3853

[5] Canelli R, Connor CW, Gonzalez M et al. Barrier enclosure during endotracheal intubation. N Engl J Med 2020; 382: 1957-1958

\section{Bibliography}

DOI https://doi.org/10.1055/a-1190-3462

Published online: 19.6.2020

Endoscopy 2020; 52: E351-E352

(c) Georg Thieme Verlag KG

Stuttgart · New York

ISSN 0013-726X

\section{ENDOSCOPY E-VIDEOS \\ https://eref.thieme.de/e-videos}

Mario Traina ${ }^{1}$, Michele Amata ${ }^{1}$, Antonino Granata ${ }^{1}$, Dario Ligresti ${ }^{1}$, Burgio Gaetano ${ }^{2}$

1 Digestive Endoscopy Service, Department of Diagnostic and Therapeutic Services, IRCCS - ISMETT, Palermo, Italy

2 Department of Anesthesia and Intensive Care, IRCCS-ISMETT, Palermo, Italy

\section{Corresponding author}

\section{Michele Amata, MD}

Digestive Endoscopy Service, IRCCS ISMETT, Via Tricomi, 5, 90127 Palermo, Italy Fax: +39-091-2192400 (specify Endoscopy Service)

michele.amata@gmail.com
Endoscopy E-Videos is a free access online section, reporting on interesting cases and new techniques in gastroenterological endoscopy. All papers include a high quality video and all contributions are freely accessible online.

This section has its own submission website at https://mc.manuscriptcentral.com/e-videos 